\section{Fever in our First Nations}

In a $C M A J$ practice article, Bagnall and colleagues describe acute rheumatic fever in a member of Canada's immigrant population. ${ }^{1}$ The same article correctly identifies Canada's First Nations as a population at risk for this disease. Social determinants of health are contributory: poverty, inadequate housing and systemic neglect. The Sioux Lookout Acute Rheumatic Working Group recently identified eight cases of acute rheumatic fever in First Nations youth, including two young children for whom the disease was fatal.

We are at a crossroads in how we perceive and respond to the inequities present for First Nations communities in Canada. Deaths from acute rheumatic fever are preventable. Inadequate housing and overcrowding play a direct role in the incidence of acute rheumatic fever, a disease unheard of in the rest of Canada.

The social and health care needs of First Nations are apparent to the Truth and Reconciliation Commission of Canada ${ }^{2}$ the United Nations, ${ }^{3}$ the Auditor General ${ }^{4}$ and the Senate. ${ }^{5} \mathrm{We}$ suggest it is also of keen interest to Canadian physicians and their patients, who may be experiencing vast health and social inequities first hand.

Janet Gordon RN, Mike Kirlew MD, Raphael Saginur MD, Natalie Bocking MD, Len Kelly MD MClinSci, Christine Kennedy MSc MD, Terri Farrell MBChB DCH, Yoko Schreiber MD MSc Sioux Lookout First Nations Health Authority (Gordon, Farrell); Division of Clinical Sciences (Kirlew), Northern Ontario School of Medicine, Sioux Lookout, Ont.; Division of Infectious Diseases (Saginur), The Ottawa Hospital, Ottawa, Ont.; Public and Preventive Medicine (Bocking), University of Toronto, Toronto, Ont.; Sioux Lookout Meno Ya Win Health Centre (Saginur, Kelly), Sioux Lookout, Ont.; Northern Ontario School of Medicine (Farrell), Sudbury, Ont.

\section{References}

1. Bagnall EM, Ho MJ, McCormick IA. A 39-yearold man with recurrent rheumatic fever. CMAJ 2015;187:50-4.

2. Truth and Reconciliation Commission of Canada [homepage]. Winnipeg. Available: www.trc.ca (accessed 2015 June 2).

3. Report of the Special Rapporteur on the rights of indigenous peoples, James Anaya: addendum on the situation of indigenous peoples in Canada. Geneva: United Nations; 2014. Available: http://unsr.james anaya.org/docs/countries/2014-report-canada-a-hrc-27 -52-add-2-en-auversion.pdf (accessed 2015 June 2).

4. 2015 spring reports of the Auditor General of Canada: Report 4 - access to health services for remote First Nations communities. Ottawa: Office of the Auditor General of Canada. Available: www. oag-bvg.gc.ca/internet/English/parl_oag_201504_04 _e_40350.html (accessed 2015 June 2).

5. Interim report of the Standing Senate Committee on Aboriginal Peoples. Housing on First Nations reserves: challenges and successes. Ottawa: The Standing Senate Committee on Aboriginal Peoples; 2015. Available: www.parl.gc.ca/Content/ SEN/Committee/412/appa/rep/rep08feb15b-e.pdf (accessed 2015 June 3)

CMAJ 2015. DOI:10.1503/cmaj.1150058

\section{Making needles less prickly}

We read with great interest the article by Curtis and colleagues, in which the authors conclude that current evidence does not support investing in ultrasound or near-infrared imaging for routine intravenous (IV) catheterization in children. ${ }^{1}$ We contend that such a broad conclusion is not warranted based on the design of the study.

Ultrasound has a role in placing the difficult IV. A recent meta-analysis ${ }^{2}$ concluded that in patients with difficult peripheral venous access, using a direct, real-time, ultrasound-guided

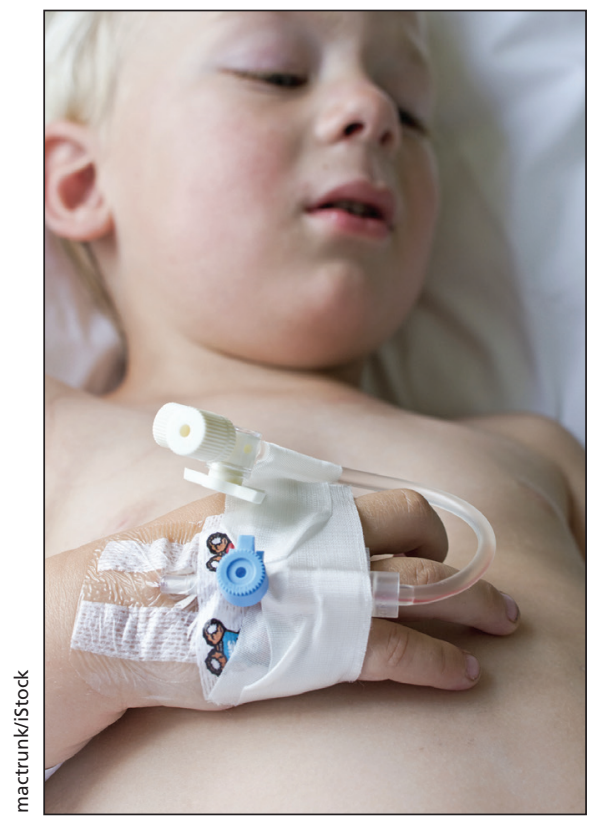

approach increased success rates of peripheral IV insertion when compared with the standard approach, but had no effect on the time or number of punctures to successful cannulation. In their discussion, Curtis and colleagues ${ }^{1}$ touch on whether the nurses were trained well enough, but then describe the training as "comprehensive."

For ultrasound-guided IV insertion, appropriate choice of vein for the technique being used, probe manipulation, and target site and needle visualization are all important skills. For freehand use of ultrasound-guided IV placement in adults, 17 (interquartile range 1527.5) attempts are required to develop a satisfactory rate of placement when using adult phantom models. ${ }^{3}$

Based on the data presented, we cannot conclude that the nurses were trained to a satisfactory standard as there was no assessment of success rates achieved on phantoms. An alternative approach is practice of a technique on patients that is supervised by recognized experts. This did not occur either.

No description of maintenance of skill using the technologies over the time of the study was described. It is concerning that only 17 nurses performed cannulation seven or more times for the study. In effect, over the 25-month period of the study, they may only have used the ancillary devices at most on two or three occasions. The majority of the 83 nurses used the technology less frequently than that. We doubt that this rate is sufficient to maintain a satisfactory skill level.

Based on their study design, we believe a more correct conclusion would have been: for routine IV placement in a setting where nurses perform IV cannulation infrequently, the addition of near-infrared and ultrasound technologies, when implemented without confirmation of skill acquisition and no facility for maintenance of skill, does not result in higher success rates of IV placement. We believe if investment in such technology is to be clinically successful, it must be accompanied by investment in training so that staff are 